\title{
Diabetic macular edema, retinopathy and age-related macular degeneration as inflammatory conditions
}

Undurti N. Das

UND Life Sciences, USA

Submitted: 7 April 2015

Accepted: 20 April 2015

Arch Med Sci 2016; 12, 5: 1142-1157

DOI: 10.5114 /aoms.2016.61918

Copyright @ 2016 Termedia \& Banach

\begin{abstract}
Diabetic macular edema (DME) and diabetic retinopathy (DR) are complications affecting about $25 \%$ of all patients with long-standing type 1 and type 2 diabetes mellitus and are a major cause of significant decrease in vision and quality of life. Age-related macular degeneration (AMD) is not uncommon, and diabetes mellitus affects the incidence and progression of AMD through altering hemodynamics, increasing oxidative stress, accumulating advanced glycation end products, etc. Recent studies suggest that DME, DR and AMD are inflammatory conditions characterized by a breakdown of the blood-retinal barrier, inflammatory processes and an increase in vascular permeability. Key factors that seem to have a dominant role in DME, DR and $A M D$ are angiotensin II, prostaglandins and the vascular endothelial growth factor and a deficiency of anti-inflammatory bioactive lipids. The imbalance between pro- and anti-inflammatory eicosanoids and enhanced production of pro-angiogenic factors may initiate the onset and progression of DME, DR and AMD. This implies that bioactive lipids that possess anti-inflammatory actions and suppress the production of angiogenic factors could be employed in the prevention and management of DME, DR and AMD.
\end{abstract}

Key words: vascular endothelial growth factor, inflammation, diabetic retinopathy, polyunsaturated fatty acids, lipoxins.

\section{Introduction}

Diabetes mellitus is now assuming epidemic proportions throughout the world, and is predicted to affect about 300 million people by 2025 . As a result of this epidemic, complications of long-standing diabetes are bound to increase. Diabetic macular edema (DME) and diabetic retinopathy (DR) constitute important complications of diabetes mellitus that represent a significant cause of visual loss that affects quality of life. Both DME and DR are preventable provided hyperglycemia is tightly controlled to near normal, a difficult task.

\section{Diabetic macular edema, diabetic retinopathy and age-related macular degeneration}

Macular edema occurs when fluid and protein deposits collect on or under the macula of the eye, producing edema that may distort central vision. As a result, it affects not only central vision but also the form and color in the direction of gaze.

\author{
Corresponding author: \\ Undurti N. Das \\ UND Life Sciences \\ 2020 S 360 ${ }^{\text {th }} \mathrm{St}$ \\ \# K-202, Federal Way \\ WA 98003, USA \\ E-mail: Undurti@hotmail.com
}


Macular edema is the final common pathway of many intraocular and systemic insults. Although macular edema may be associated with protean underlying conditions, it is commonly seen following intraocular surgery, venous occlusive disease, $\mathrm{DR}$, and posterior segment inflammatory disease. Diagnosis of macular edema is made by performing fluorescein angiography and optical coherence tomography. A variety of approaches to the treatment of macular edema have been attempted, with a variable degree of success. These options include topical and systemic steroids, topical and oral non-steroidal anti-inflammatory agents, laser photocoagulation treatment, immunomodulators, intravitreal injection of triamcinolone, and pars plana vitrectomy [1].

It may be noted here that DME, DR and neovascular age-related macular degeneration (AMD) are frequent retinal degenerative diseases, and are responsible for the majority of cases of blindness due to retinal disease. These conditions predominantly affect the central macula, and are associated with the presence of retinal edema and an aggressive inflammatory repair process that accelerates disease progression. The associated retinal edema and the inflammatory repair process are directly involved in the breakdown of the blood-retinal barrier (BRB). Yet, the underlying alterations to the BRB caused by these diseases are likely to be very different. Though coexistence of DR and AMD is relatively uncommon, it is believed that the inflammatory repair responses associated with DR and neovascular AMD may be cumulative and, in patients affected by both, could result in chronic diffuse cystoid edema [2].

The key pathophysiological processes in DME, DR and AMD appear to be breakdown of the blood-retinal barrier, which allows fluid to accumulate in the retinal tissue via special water fluxes, inflammatory processes and an increase in vascular permeability. Furthermore, ischemic conditions prevail in these conditions, in which there seems to be a key role for various cytokines, angiotensin II, prostaglandins (PGs), vascular endothelial growth factor (VEGF) and deficiency of anti-inflammatory bioactive lipids derived from polyunsaturated fatty acids (PUFAs) [3-7].

Though the exact mechanism(s) that initiate and render DME, DR and AMD progressive are not clear, there is evidence to suggest that oxidative stress $[8,9]$, retinal vascular endothelial dysfunction [10] and consequent increased vascular permeability [11], enhanced expression of adhesion molecules [12, 13] and increased production and action of pro-inflammatory cytokines play a significant role [14-18], suggesting that low-grade inflammation has a dominant role in these conditions. Since the retina is rich in $n-3$
PUFAs and their metabolites lipoxins, resolvins, protectins and maresins have anti-inflammatory actions, it is likely that these molecules may have a role in DME, DR and AMD. In this context, it is important to briefly review the metabolism of essential fatty acids as relevant to their role in DME, DR and AMD.

\section{Metabolism of essential fatty acids}

The essential fatty acids (EFAs) $n-3 \alpha$-linolenic acid (ALA) and $n-6$ linoleic acid (LA) are widely distributed in our diet, and fatty acids are metabolized by the same set of enzymes, $\Delta^{6}$ and $\Delta^{5}$ desaturases and elongases, into their long-chain metabolites, namely: ALA to eicosapentaenoic and docosahexaenoic acids (EPA and DHA respectively) and LA to arachidonic acid (AA) (see Figure 1) [19-21]. All cell membranes incorporate both EFAs and their long-chain metabolites AA, EPA and DHA mainly into their phospholipid (PL) fraction. Various stimuli such as growth factors including epidermal growth factor (EGF) and VEGF, various cytokines and free radicals have the ability to activate phospholipase $A_{2}\left(P L A_{2}\right)$, which is a membrane bound enzyme that induces the release of AA, EPA and DHA to form their respective products. AA, EPA and DHA are metabolized by cyclo-oxygenases (COXs), lipoxygenases (LOXs), and cytochrome P450 (Cyp450) enzymes, which results in the formation of several products (see Figure 2). AA forms a precursor to pro-inflammatory PGs and thromboxanes (TXs) of 2 series and leukotrienes (LTs) of 4 series (though not all prostaglandins formed are pro-inflammatory; for instance, prostacyclin from $A A$ and $P G E_{1}$ from dihomo-gamma-linolenic acid (DGLA) have anti-inflammatory actions), whereas EPA forms a precursor to 3 series PGs, TXs and 5 series LTs. It is noteworthy that AA can also give rise to lipoxins, which are potent anti-inflammatory molecules. Similarly, EPA gives rise to resolvins and DHA to protectins, which possess significant anti-inflammatory and wound healing properties and show cytoprotective actions. Thus, $A A, E P A$ and DHA, under some well-defined conditions, form specific anti-inflammatory lipoxins, resolvins and protectins, respectively, that protect various cells and tissues against insults and augment recovery of the target tissues and organs to normal and reestablish homeostasis (see Figure 3). Since the retina and brain are rich in $A A$, $D H A$ and EPA (DHA > AA > EPA), it is reasonable to assume that adequate amounts of lipoxins, resolvins and protectins are formed under normal physiological conditions to protect the retina and other neuronal cells from various insults and diseases [19-21]. This evidence indicates that PUFAs are not only biologically active by themselves but are also capable of giving rise to several biological- 
ly active metabolites that play an important role in physiological and pathological processes.

Diabetic macular edema, diabetic retinopathy and age-related macular degeneration are inflammatory conditions

Several lines of evidence indicate that DME, DR and AMD are low-grade inflammatory conditions. It is noteworthy that unlike the classical inflammatory signs such as pain (dolor), heat (calor), redness (rubor), swelling (tumor), and loss of function (functiolaesa), the inflammatory signs in $D M E, D R$ and $A M D$ are at a microscopic level. For instance, these microscopic features of inflammation seen in DME, DR and AMD include: change in the retinal vascular diameter in the form of vessel dilatation, an alteration in blood flow in these vessels, exudation of plasma proteins, and leucocyte adhesion, accumulation and migration [22-27]. These local microscopic signs of inflammation in these conditions are characterized by increased production of tumor necrosis factor- $\alpha$ (TNF- $\alpha$ ),

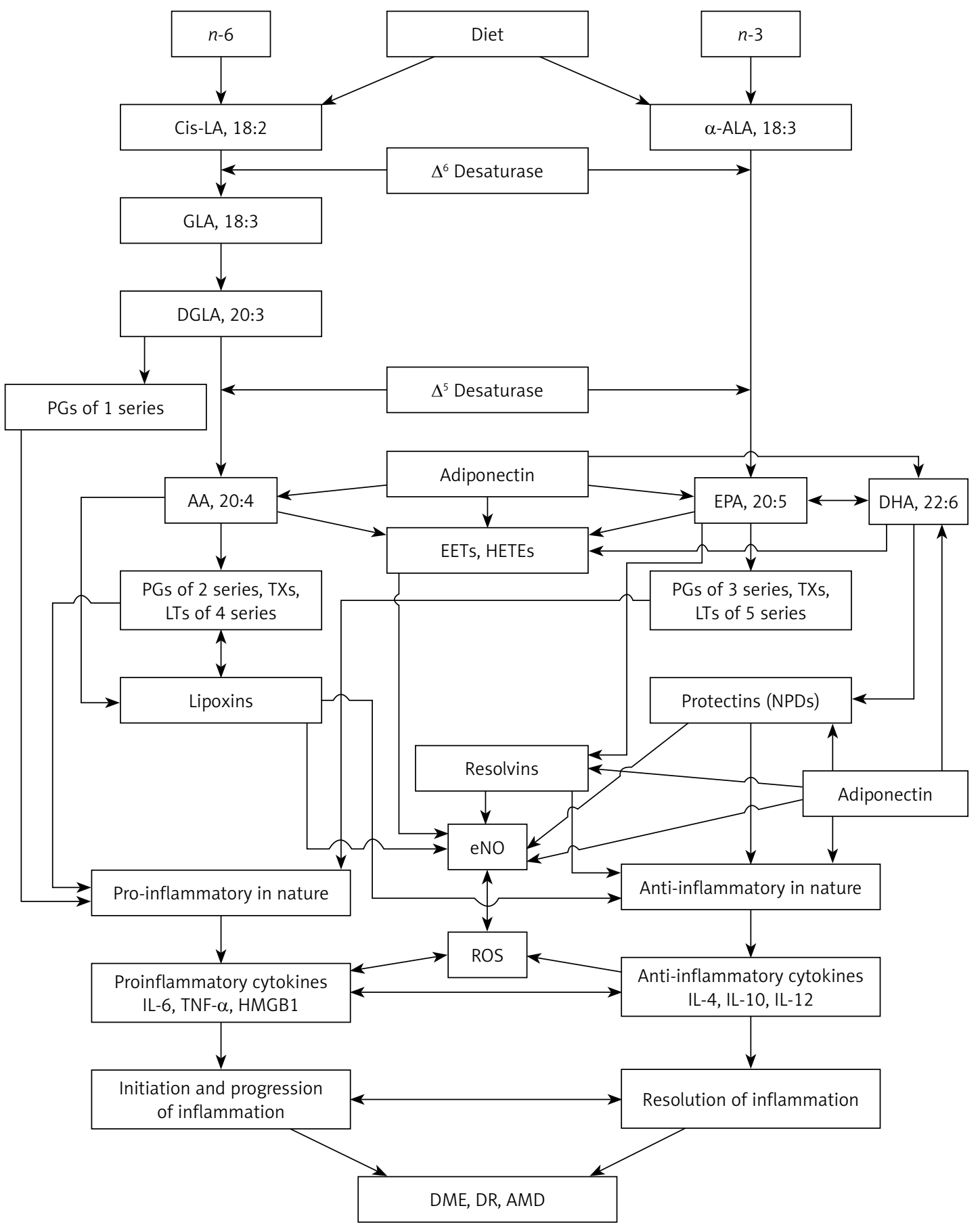

Figure 1. Scheme showing metabolism of essential fatty acids and their role in inflammation, DME, DR and AMD 


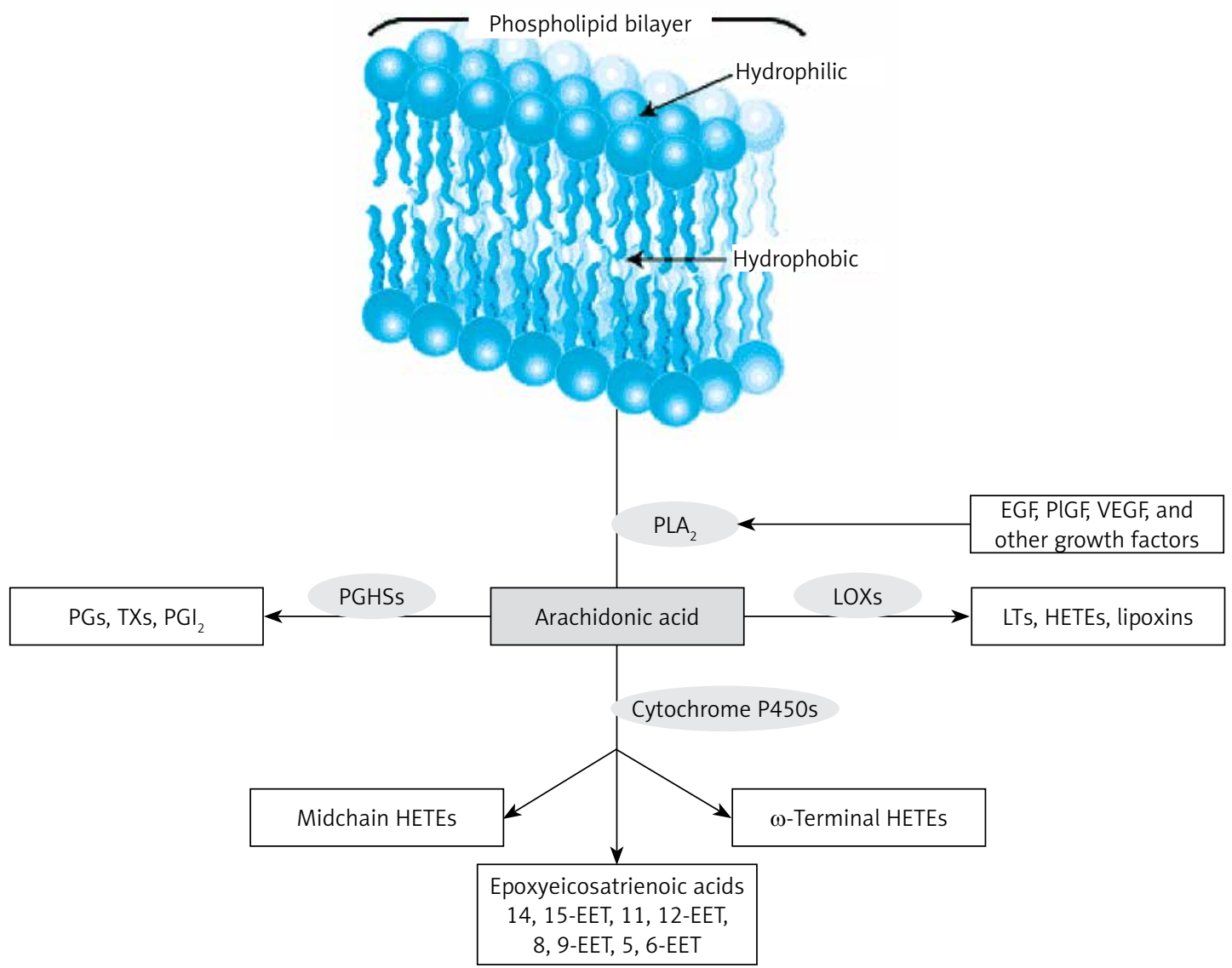

Figure 2. Metabolism of AA. Prostaglandin $\mathrm{H}$ synthase (PGHSs) metabolize AA to prostaglandins, thromboxanes and prostacyclin. LOXs metabolize AA to leukotrienes, hydroxyeicosatetraenoic acids (HETEs) and lipoxins. The P450 monooxygenases metabolize AA to midchain HETEs, $\omega-3$ terminal HETEs and the epoxyeicosatrienoic acids (EETs). EETs have anti-inflammatory actions and so are likely to play a role in AMD, DME and DR. Even EPA may form compounds similar to those that are formed from AA as shown here

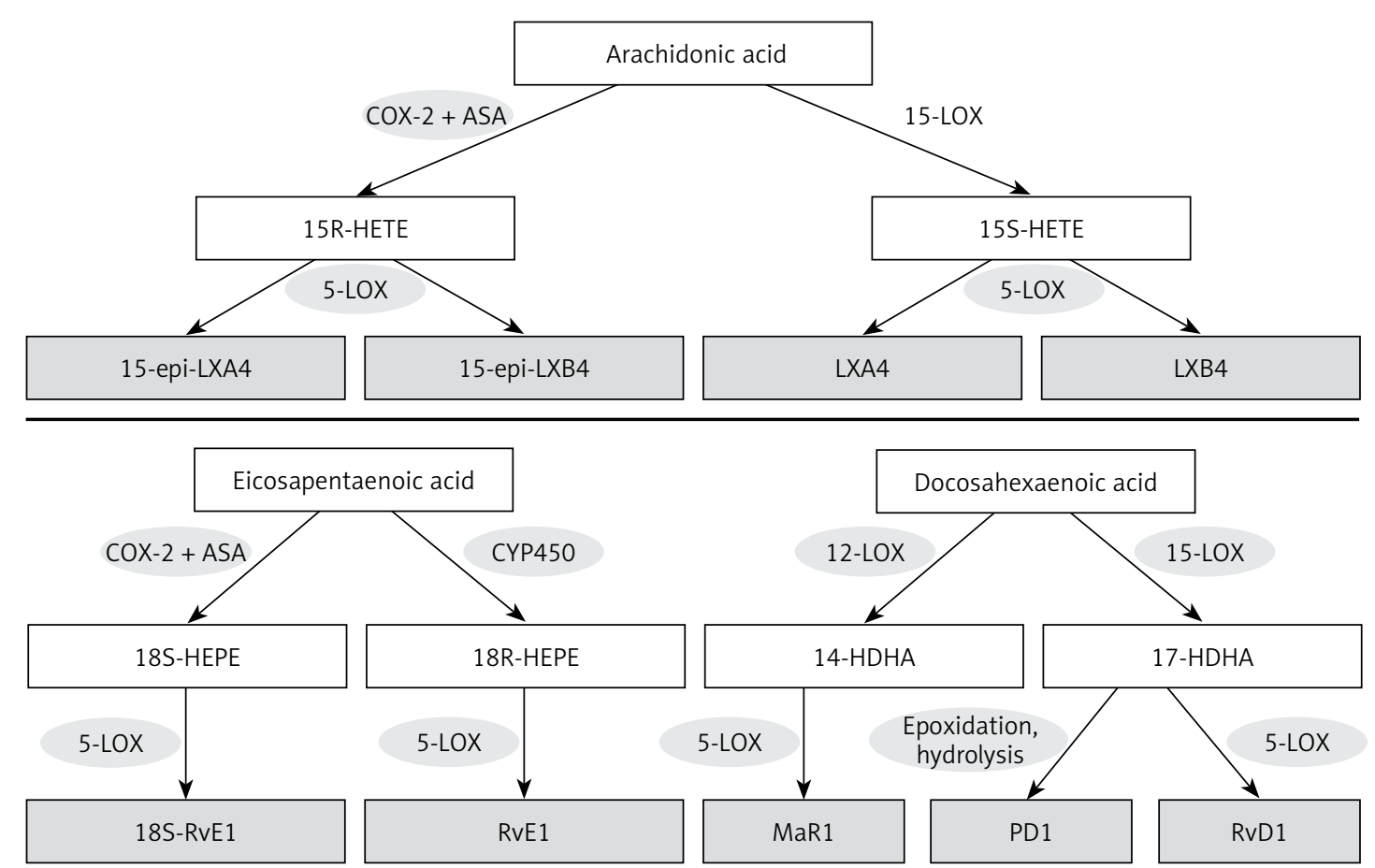

Figure 3. Scheme showing the formation of $\mathrm{LXA}_{4}$ from AA, resolvin E1 (RvE1) from EPA and protectin D1 (PD1), resolvin D1 (RvD1) and maresin (MaR1) from DHA 
VEGF, PGs, enhanced expression of intercellular adhesion molecule-1 (ICAM-1) on the vasculature, $\beta 2$ integrins on the leucocytes, vascular cell adhesion molecule-1 (VCAM-1) and VLA-4 and oxidative stress [14-18, 22-37]. These pro-inflammatory events enhance adherence of leukocytes and macrophages, and accumulation within the vasculature of the retina occurs [38-42], which precedes the occurrence of DME, DR and AMD. Leukocyte and macrophage adherence and migration can induce vascular dysfunction as a result of increased production of reactive oxygen species (ROS) and lipid peroxidation, which results in a subtle breakdown of the blood-retinal barrier, premature endothelial cell injury and death, and capillary ischemia/ reperfusion [43]. Diabetic rats treated with ICAM-1 or $\beta 2$ integrin neutralizing antibodies showed decreased leucocyte adhesion [31, 38], the disrupted blood-retinal barrier returned to normal $[22,38]$, and endothelial cell injury and death were abrogated $[22,43]$. In addition, mice deficient in the ICAM-1 or $\beta 2$ integrin gene CD18 when made diabetic showed near normal retinal vasculature [22, 44]. In this context, it is interesting to note that patients with rheumatoid arthritis who are on high doses of aspirin showed less severe DR [45]; and aspirin prevented histopathological features of DR [46], implying that non-steroidal anti-inflammatory drugs (NSAIDs) that inhibit inflammation by blocking/suppressing the production of pro-inflammatory PGs are of benefit in DR and, possibly, in AMD and DME. This evidence $[45,46]$ is in support of the role of pro-inflammatory eicosanoids in DME, DR and AMD [47-51]. In this context, it should be noted that in patients with $D R$, reduced plasma and vitreal concentrations of $\mathrm{PGE}_{1}$ and $\mathrm{PGI}$ were reported [52-55], while those of TXs and LTs were increased [50, 54-56]. These results suggest that in DME, DR and AMD there is an imbalance between vasodilator and platelet anti-aggregator $\mathrm{PGE}_{1}$ and $\mathrm{PGI}_{2}$ and platelet aggregator and vasoconstrictor TXA and LTs, leading to ischemic vasoconstriction of retinal vessels and enhanced platelet aggregation. Even the concentrations of $\mathrm{PGE}_{2}$, a vasodilator eicosanoid, have been shown to be decreased in DR [53], indicating that vasodilator actions of various PGs are more important in the pathobiology of DME, DR and AMD than their platelet anti-aggregator actions. This implies that hypoxia has a more dominant role in these diseases. Aspirin and other NSAIDs are known to suppress the synthesis of TXA and LTs and either enhance or do not interfere with $\mathrm{PGI}_{2}$ synthesis and thus alter the ratio between $P G I_{2}$ and $T X A_{2}$ more in favor of $P G I_{2}$, which is expected to nullify the vasoconstrictor actions of TXA, and leukotrienes, which is of benefit in DME, DR and AMD.

It is noteworthy that aspirin selectively enhances $\mathrm{PGI}_{2}$ synthesis and $\mathrm{NO}$ and heme oxygenase-1 activity (which leads to enhanced generation of carbon monoxide, (CO) and decreases levels of plasma asymmetrical dimethylarginine (ADMA), a competitive inhibitor of NO [57-61]. These changes in $\mathrm{PGI}_{2}, \mathrm{NO}$ and $\mathrm{CO}$ and ADMA levels may account for some of the beneficial actions of aspirin in DME, DR and AMD. In addition, aspirin augments the production of lipoxin $A_{4}\left(L X A_{4}\right)$, a potent anti-inflammatory, platelet anti-aggregator and vasodilator [62-64] that could also be responsible for its beneficial effect in these ocular conditions. Furthermore, NO synthase and COX-2 enzymes act together to enhance production of $\mathrm{PGE}_{2}$, which may contribute to retinal cell death in diabetes and development of DR, and aspirin, at least in part, inhibits retinopathy by inhibiting this $\mathrm{NO} / \mathrm{COX}-2$ axis (by reducing $\mathrm{PGE}_{2}$ production) [65]. $\mathrm{LXA}_{4}$ is a potent inducer of NO generation [66-68] that, in turn, quenches superoxide anion and thus suppresses $\mathrm{PGE}_{2}$ production and bring about its cytoprotective action on retinal cells. In addition, LXA4 is also a suppressor of free radical generation [69-71].

In this context, it is relevant to note that antiinflammatory interleukin-10 (IL-10) induces expression of heme oxygenase-1 (HO-1), a stressinducible protein with a potential anti-inflammatory effect, via a p38 mitogen-activated protein kinase-dependent pathway. Inhibition of HO-1 protein synthesis or activity reversed the inhibitory effect of IL-10 on production of TNF- $\alpha$ induced by lipopolysaccharide (LPS). CO, one of the products of HO-1-mediated heme degradation, was found to be involved in the anti-inflammatory effect of IL-10 both in vitro and in vivo $[72,73]$. LXA $_{4}$ also has actions similar to IL-10 to enhance the production of $\mathrm{CO}$ [74-76].

$\mathrm{LXA}_{4}$, an endogenous 12/15-LOX product, inhibited inflammation and significantly increased re-epithelialization in corneal wounds. 12/15LOX $^{(-/)}$mice showed impaired induction and topical LXA 4 restored $\mathrm{HO}-1$ expression in 12/15$\mathrm{LOX}^{(-/)}$mice and amplified HO-1 gene expression in human corneal epithelial cells. Similarly, $\mathrm{HO}$ $2^{(--)}$mice, which fail to induce $\mathrm{HO}-1$, also demonstrated exacerbated inflammation in response to injury, which correlated with a significant reduction in endogenous $\mathrm{LXA}_{4}$ formation. These results suggest that $\mathrm{LXA}_{4}, 12 / 15$-LOX and $\mathrm{HO}$ systems function in concert with each other to control inflammation and regulate each other's formation and action [77].

Anti-inflammatory cytokines IL-4 and IL-10 significantly up-regulated 12/15-LOX mRNA expression, which triggers the conversion of $A A$, EPA and DHA to lipoxins, resolvins, protectins and maresins, suggesting a mechanism by which they suppress inflammation [78, 79]. Furthermore, there is evidence to support the contention that 
excess production of $\mathrm{PGE}_{2}$ and $\mathrm{LTS}$ could trigger the production of $\mathrm{LXA}_{4}$, suggesting that triggering of anti-inflammatory events occurs once the pro-inflammatory molecules reach a peak. Studies showed that enhanced production of $\mathrm{PGE}_{2}$ and LTs upon whole-body exposure to gamma-radiation, cobalt-60, and cyclotron neutrons stimulated $\mathrm{LXA}_{4}$ production at the expense of the pro-inflammatory AA-derived $\mathrm{LTB}_{4}$, since it was noted that the anti-inflammatory metabolite 15-HETE (the precursor of LXs) shows peaking at $72 \mathrm{~h}$ following exposure to radiation/UVB coinciding with the gradual decrease in $\mathrm{PGE}_{2}$ and LTs formation, such that there is a smooth shift in the synthesis of eicosanoids from pro-inflammatory $\mathrm{PGE}_{2}$ and LTs to 15 -HETE and LXs in order to initiate resolution of radiation-induced damage [80-82]. Thus, the initial enhanced synthesis of pro-inflammatory $P G E_{2}$ and $L T s$ seems to be essential to trigger subsequent formation of anti-inflammatory $\mathrm{LXA}_{4}$. It is noteworthy that $\mathrm{PGE}_{2}$ enhances the production of IL-10, an anti-inflammatory cytokine [83], while IL- 6 release is enhanced by $\mathrm{PGE}_{2}$ in the presence of
anti-IL-10, whereas both IL-10 and PGE ${ }_{2}$ inhibited LPS-stimulated IL- 6 and TNF- $\alpha$ and selective inhibition of COX-2 or addition of anti-IL-10 reversed these effects [84]. Exogenous IL-10 suppressed COX-2 production [85]. These results suggest that $\mathrm{PGE}_{2}$ induces the production of $\mathrm{IL}-10$, which, in turn, downregulates IL-6, TNF- $\alpha$, and COX-2 activity in order to restore homeostasis [82-85].

This complex network of positive and negative feedback regulatory events among PGs, LTs, cytokines, NO, CO and $\mathrm{LXA}_{4}$ and cytokines that participate in the pathogenesis of DME, DR and AMD implies that pro-inflammatory stimuli-induced generation of PGE ${ }_{2}$ TXA, LTs and IL-6 and TNF- $\alpha$ and decreased production of $\mathrm{NO}, \mathrm{CO}$ and $\mathrm{LXA}_{4}$ not only initiate inflammation but also have the ability to trigger generation of anti-inflammatory molecules such as IL-4, IL-10, LXA, NO and CO at an appropriate time of the inflammatory process in order to restore homeostasis (Figure 4). If this well-conceived, well-designed and orderly natural positive and negative regulatory system failed, it would lead to perpetuation of low-grade inflam-

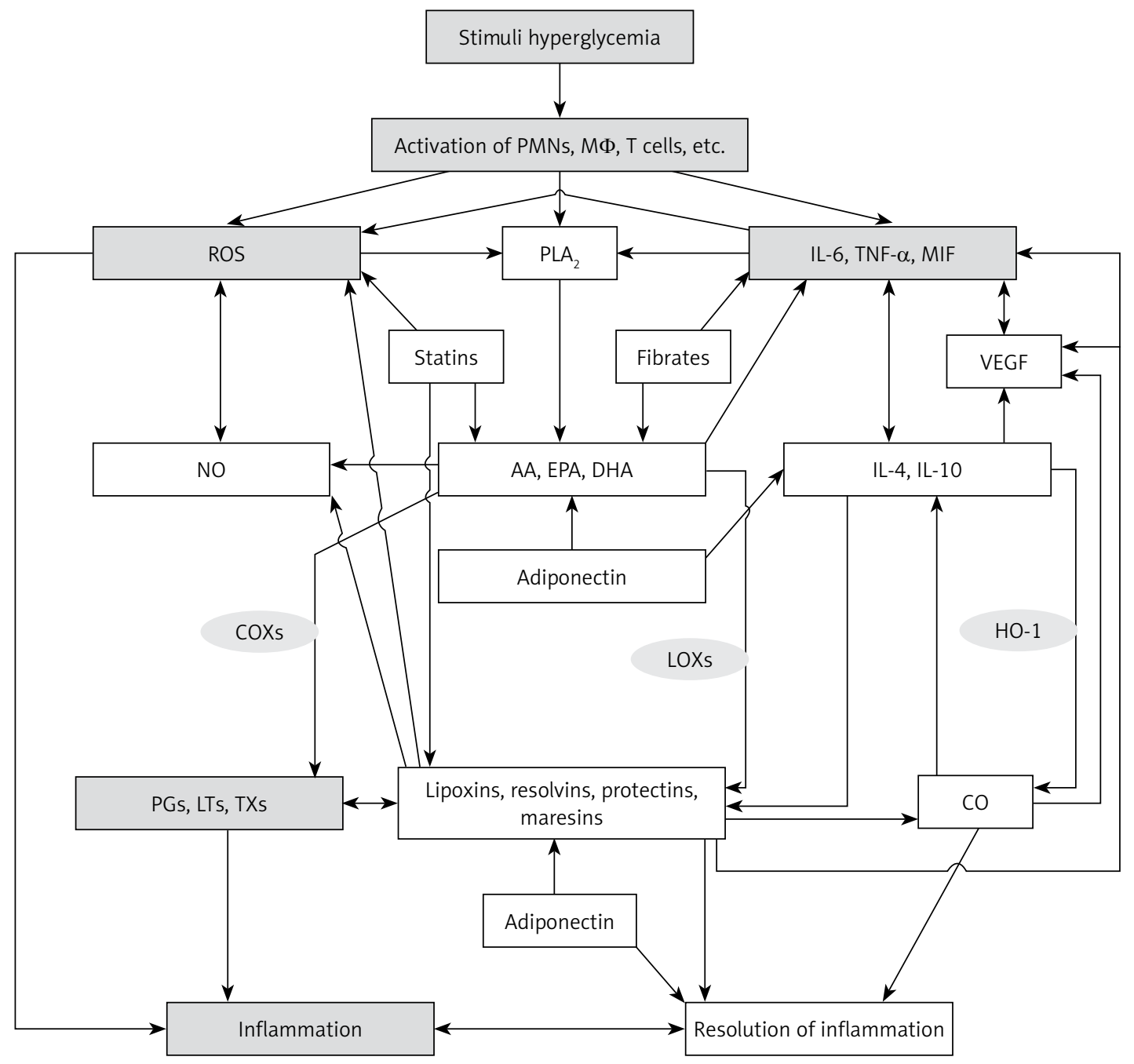

Figure 4. Scheme showing positive and negative feedback regulation between pro- and anti-inflammatory molecules 
mation seen in DME, DR and AMD. Thus, methods designed to augment $\mathrm{NO}, \mathrm{CO}$ and $\mathrm{LXA}_{4}$ generation are expected to restore homeostasis and prevent, reverse and arrest the progression and/or even ameliorate DME, DR and AMD.

\section{Vascular endothelial growth factor in diabetic macular edema, diabetic retinopathy and age-related macular degeneration}

VEGF is induced by hypoxia and it has been implicated in the development of iris and retinal neovascularization (NV) in ischemic retinopathies $[86,87]$. VEGF is known to be a potent mediator of vascular permeability and pro-inflammatory molecule $[88,89]$. Increased VEGF immunoreactivity in ganglion cells of rats with oxygen-induced ischemic retinopathy and in ganglion cells, the inner plexiform layer, and some cells in the inner nuclear layer of rats with experimental autoimmune uveoretinitis (EAU) has been reported. VEGF staining was also increased in the retina and iris of patients with ischemic retinopathies including DR and retinal vascular occlusive disease, wherein VEGF was primarily localized within retinal neurons and retinal pigmented epithelial cells [86, 90]. It was reported that VEGF contributes to BRB breakdown and blockage of VEGF signaling reduced macular edema [90, 91]. VEGF is a potent endothelial-specific mitogen, and a direct correlation between vitreal VEGF levels and severity of macular edema and retinopathy $[90,91]$ has been reported. Hyperglycemia is a potent stimulator of VEGF secretion $[92,93]$. VEGF inhibits the apoptosis of endothelial cells $[94,95]$, which leads to the generation of immature vascular structures that are fragile and hence bleed easily, which favors retinal detachment and consequent blindness. The fact that anti-VEGF therapies arrest or slow the progress of DR $[96,97]$, though they are not always effective, is in support of an important role of VEGF in DME and DR.

It is evident from the preceding discussion that strategies developed to prevent an increase in the production of TNF- $\alpha$, ICAM-1, VCAM and VEGF and prevent leukocyte activation could be of benefit in preventing or arresting the progression of DME, DR and AMD. In this context, the role of PUFAs and their anti-inflammatory metabolites needs particular attention.

\section{Polyunsaturated fatty acids and their products lipoxins, resolvins and protectins in diabetic macular edema, diabetic retinopathy and age-related macular degeneration}

It is known that PUFAs and their anti-inflammatory products lipoxins, resolvins, protectins and maresins inhibit the production of IL- 6 and TNF- $\alpha$ and suppress the expression of ICAM- 1 and
VCAM and induce resolution of the inflammatory process [98-105]. This implies that presence of appropriate amounts of PUFAs (including $A A$ ) and formation of their anti-inflammatory products lipoxins, resolvins, protectins and maresins serve as negative feedback inhibitors of pro-inflammatory IL-6, IL-2 and TNF- $\alpha$ formation and action and thus suppress inflammatory events and restore homeostasis. In addition, PUFAs and lipoxins, resolvins, protectins and maresins suppress whereas pro-inflammatory prostaglandins (especially $\mathrm{PGE}_{2}$ and $\mathrm{PGE}_{1}$ ) enhance VEGF production [106-114]. It was reported that epoxy metabolites of DHA formed due to the action of cytochrome P450 activity inhibit VEGF- and fibroblast growth factor 2 -induced angiogenesis in vivo, and suppress endothelial cell migration and protease production in vitro via a VEGF receptor 2-dependent mechanism [114]. It is likely that similar epoxy metabolites formed from AA and EPA may also inhibit VEGF production and action. These results suggest that several metabolites of AA, EPA and DHA that have both pro- and anti-inflammatory actions can either enhance or suppress the production and action of VEGF. This indicates that maintaining a delicate balance between these pro- and anti-inflammatory products of AA, EPA and DHA and their action on VEGF, and pro- and anti-inflammatory cytokines ultimately determines either continuation or persistence of inflammation and suppression of inflammation and restoration of homeostasis (see Figures 4 and 5). These results imply that it is not just the presence of adequate concentrations of AA, EPA and DHA that is essential to suppress inflammation and restore normalcy but it is essential for the formation of appropriate amounts of their anti-inflammatory lipoxins, resolvins, protectins, maresins and epoxy metabolites to trigger the anti-inflammatory process and resolve inflammation. In view of this, activities of $\Delta^{6}$ and $\Delta^{5}$ desaturases (which are essential to metabolize essential fatty acids LA and ALA to their respective long-chain products: $A A$ and EPA and DHA, respectively), COX-2 and 5-, 12- and 15-lipoxygenases (which are needed for the formation of lipoxins, resolvins, protectins and maresins) and cytochrome P450 activity (to form relevant epoxy metabolites) (see Figures 1-3), several co-factors needed for the activities of these enzymes and their genetic polymorphisms may play a significant role in the pathobiology of DME, $D R$ and $A M D$ by influencing the formation of $A A$, EPA and DHA, lipoxins, resolvins, protectins, maresins and epoxy metabolites of AA, EPA and DHA.

The involvement of PUFAs and their metabolites in DME, DR and AMD is further supported by the observation that in mice, hyperoxia-induced premature retinopathy can be inhibited by EPA and DHA [115]. This and other studies showed 


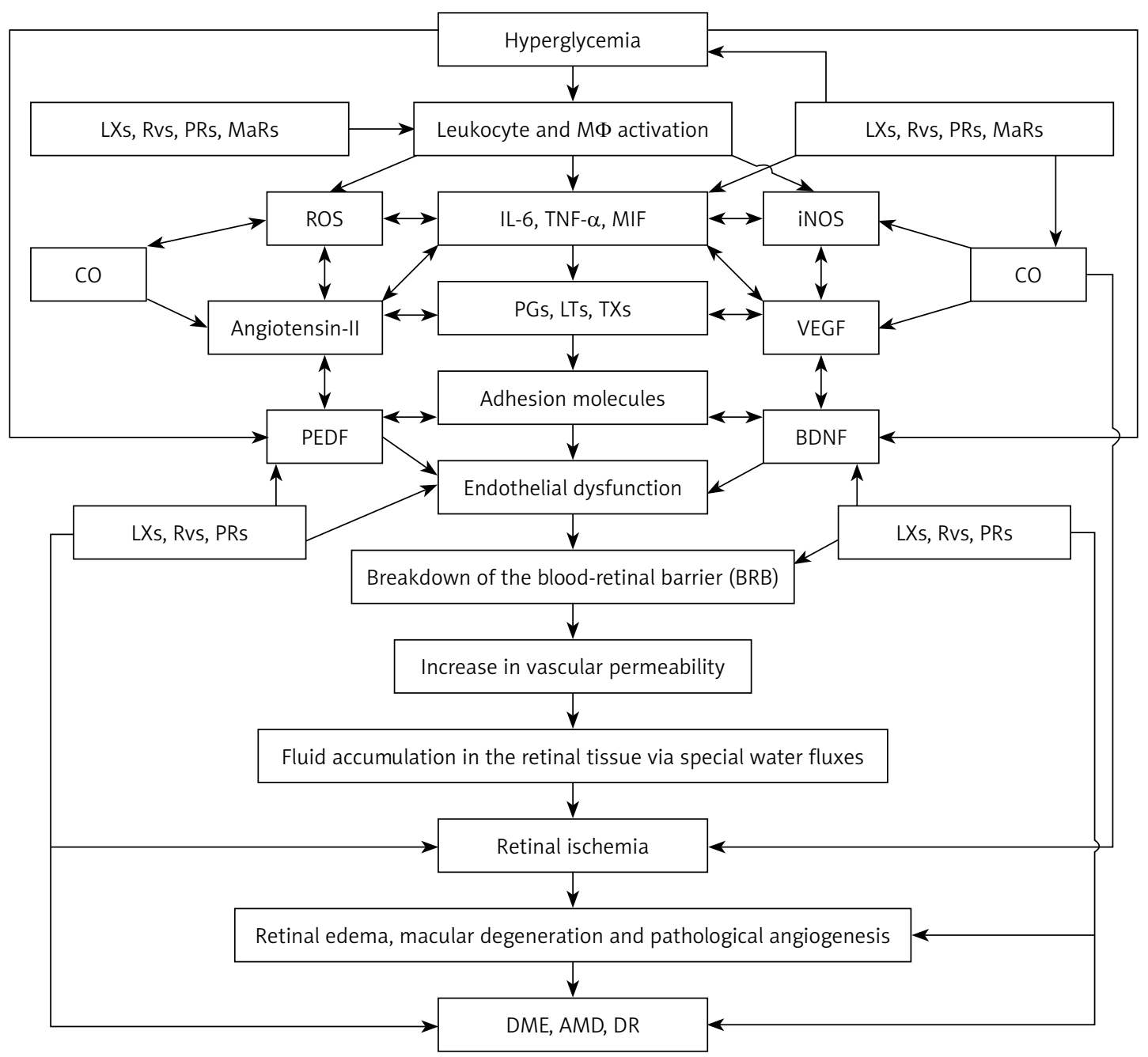

Figure 5. Scheme showing possible sequence of events that lead to the development of DME, DR and AMD. Hyperglycemia causes activation of leukocytes, macrophages and lymphocytes, resulting in increased production of reactive oxygen species (ROS) and pro-inflammatory IL-6, TNF- $\alpha$, macrophage migration inhibitory factor (MIF) and other cytokines. These cytokines also enhance ROS production and enhance the production and release of pro-inflammatory eicosanoids ((prostaglandins (PGs), leukotrienes (LTs) and thromboxanes (TXs)) by activating cell membrane bound phospholipase $\mathrm{A}_{2}$ $\left(P L A_{2}\right)$ that induces the release of polyunsaturated fatty acids: arachidonic acid (AA), eicosapentaenoic acid (EPA) and docosahexaenoic acid (DHA), which are precursors of PGs, LTs and TXs. IL-6, TNF- $\alpha$, MIF, PGs, LTs and TXs enhance the expression of adhesion molecules, which leads to adhesion of leukocytes to endothelial cells, resulting in endothelial dysfunction due to the action of ROS released by adherent leukocytes on endothelial cells. Eicosanoids, cytokines, ROS and endothelial dysfunction can cause breakdown of the blood-retinal barrier, resulting in increased vascular permeability and fluid accumulation in the retinal tissue via special water fluxes. This leads to retinal ischemia and increased production of VEGF and pathological angiogenesis, events that result in the initiation and progression of retinal edema, macular degeneration and DR. Increased production of IL-6, TNF- $\alpha$, MIF, and eicosanoids also induces enhanced production of VEGF and iNOS, which have pro-inflammatory actions and so are capable of producing endothelial dysfunction, retinal ischemia and pathological angiogenesis. Leukocytes are activated, and when diabetes is associated with hypertension there could be enhanced production of angiotensin-II, which has pro-inflammatory actions. Angiotensin-II is capable of enhancing ROS generation by leukocytes and stimulates increased production of IL-6, TNF- $\alpha$ and MIF and pro-inflammatory eicosanoids. Under normal physiological conditions, AA, EPA and DHA can also give rise to the formation of anti-inflammatory lipoxins (LXs), resolvins (RVs), protectins (PRs) and maresins (MaRs), which suppress leukocyte activation, ROS generation, PGs, LTs and TXs, formation of angiotensin-II, VEGF production and activation of iNOS. These events would ultimately result in suppression of inflammation and preservation of the blood retinal barrier and prevention of retinal ischemia and thus amelioration of DME, DR and AMD. Lipoxins, resolvins and protectins enhance the production of $\mathrm{CO}$, a vasodilator and anti-inflammatory gas that also has cytoprotective properties. $\mathrm{CO}$ can suppress the production of ROS. PEDF produced by retinal pigment epithelial cells has anti-inflammatory, cytoprotective and anti-oxidant properties and is capable of protecting retinal cells and thus preventing DME, AMD and DR. Hyperglycemia suppresses the production of PEDF and thus may initiate the onset of DME, DR and AMD. It is not yet known whether PEDF can enhance the formation of lipoxins, resolvins and protectins and vice versa, though this is a distinct possibility. PEDF suppresses the formation of ROS, IL-6, TNF- $\alpha$ and MIF and expression of adhesion molecules and preserves the blood retinal barrier. BDNF is another neurotrophic factor that preserves retinal cell integrity, enhances formation of lipoxins, resolvins, protectins and maresins and prevents DME, DR and AMD. For details see the text 
that suppression of VEGF production and neoangiogenesis and retinopathy could be correlated with increased formation of resolvins from EPA and DHA in the prevention and/or arrest of DR and similar conditions [115-118]. Previously, we found that both LA and AA inhibited high-glucose-induced retinal vascular endothelial damage [119]. ALA, the precursor of EPA and DHA, suppressed high-glucose-induced VEGF secretion in streptozotocin-induced diabetic animals [120]. Thus, it appears that the $n-3$ PUFAs ALA, EPA and DHA are capable of suppressing pathological VEGF secretion [115-120]. On the other hand, AA suppresses VEGF production in an indirect fashion. For instance, selective COX-2 inhibition was reported to downregulate VEGF and thus decrease angiogenesis [121]. This is supported by the observation that persistent induction of COX-2 expression and resultant elevation in $\mathrm{PGE}_{2}$ synthesis enhanced VEGF expression and angiogenesis [107, 122]. Furthermore, the enzyme 15-LOX-2 (15-lipoxygenase-2) utilizes AA to synthesize 15(S)-hydroxyeicosatetraenoic acid (15-HETE), which, in turn, suppresses VEGF expression [123]. Thus, COX-2 enhances whereas 15-LOX-2 suppresses VEGF expression, implying a role for $\mathrm{PGE}_{2}$, a pro-inflammatory molecule, and lipoxins and protectins, anti-inflammatory bioactive lipids (whose synthesis requires the 15-LOX enzyme) (see Figure 3 ). Thus, $\mathrm{PGE}_{2}$ on one hand and lipoxins and protectins on the other have opposite actions on the expression of VEGF. This is understandable since $\mathrm{PGE}_{2}$ is a pro-inflammatory molecule, whereas $L_{X A}$ is an anti-inflammatory substance and inflammation is known to induce angiogenesis while suppression of inflammation is accompanied by regression of angiogenesis. In addition, VEGF has pro-inflammatory actions $[88,89]$. Thus, a close relationship exists among COX-2, 15-LOX-2, cytochrome P450 enzymes, $\mathrm{PGE}_{2}$, lipoxins, resolvins, protectins and maresins levels, inflammation and VEGF expression. Since DME, DR and AMD are inflammatory diseases, it is likely that in these conditions there is increased expression of COX-2 and enhanced levels of $\mathrm{PGE}_{2}$ and leukotrienes in the plasma and vitreal fluid $[49,50,55,56,124]$. Since LXA $_{4}$ is a potent suppressor of inflammation and $\mathrm{PGE}_{2}$ synthesis [7, 19, 20, 125-127], it is reasonable to propose that its levels are likely to be low in DME, $\mathrm{DR}$ and $\mathrm{AMD}$.

It is interesting to note that PUFAs, especially $\mathrm{LXA}_{4}$ and $\mathrm{AA}$, augmented the production of BDNF (brain-derived neurotrophic factor), a neurotrophic factor that is needed for the survival of retinal neuronal cells $[128,129]$ (Das UN, unpublished data). In addition, BDNF binds to $\mathrm{LXA}_{4}$ and $\mathrm{AA}$ and other PUFAs rather avidly and thus bring about some of its beneficial actions [130]. This interaction between BDNF and PUFAs could be yet anoth- er mechanism by which PUFAs and LXA $_{4}$ protect retinal neuronal cells from undergoing degeneration due to DME, DR and AMD (Figure 5).

\section{Implications of the current knowledge and future perspectives}

There is evidence to suggest that DME, DR and $A M D$ are low-grade inflammatory conditions since enhanced levels of IL-6, TNF- $\alpha$, and VEGF in the plasma and vitreal fluid, increased expression of ICAM-1 and VCAM and leukostasis and enhanced generation of ROS by infiltrating leukocytes and decreased anti-oxidants have been reported in them. The role of inflammation in DME, DR and $A M D$ is rather interesting in the light of the observation that obesity, hypertension, hyperlipidemias, and insulin resistance, which are closely associated with these conditions (especially DR), are also low-grade systemic inflammatory conditions [131-139]. It is likely that inflammatory changes seen in DME, DR and AMD are confined to the local tissue, whereas in hypertension, type 2 diabetes mellitus and metabolic syndrome they are more systemic in nature. This may mean that retinal changes similar to those seen in DME, DR and AMD may also occur in other inflammatory conditions such as rheumatoid arthritis, lupus, and scleroderma [140]. Since alterations in essential fatty acid metabolism and eicosanoids are also known to occur in these rheumatological conditions [139, 141-146], it may explain the coexistence of retinal changes similar to those seen in DME, DR and AMD.

There are several options available to manage $D M E, D R$ and $A M D$, including topical and systemic steroids, topical and oral non-steroidal anti-inflammatory agents, laser photocoagulation treatment, immunomodulators, intravitreal injection of triamcinolone, and pars plana vitrectomy (reviewed in [147-150]). Despite these treatment options, DME, DR and AMD tend to progress and cause considerable vision loss and morbidity and affect quality of life. In view of this, development of newer therapeutic strategies is certainly welcome.

Though anti-VEGF therapies are reasonably beneficial in DME, DR and AMD [148-150], many patients show an inadequate response. The retina is rich in n-3 PUFAs, suggesting that these fatty acids and their products may have a significant role in the structural and functional integrity of the retina. It is likely that alterations in the levels and metabolism of PUFAs could trigger the initiation and progression of DME, DR and AMD and the associated angiogenic process. We and others observed a decrease in the plasma levels of $A A$, EPA and DHA in both type 1 and type 2 diabetes mellitus [151-153]. Our own studies and those of others [154-159] showed that PUFAs and various 
prostaglandins modulate the occurrence of both type 1 and type 2 diabetes mellitus, indicating a close relationship among PUFAs and their products and diabetes mellitus, implying that these lipid molecules may have a role in DR.

IL-6, TNF- $\alpha$, VEGF and other growth factors activate phospholipase $A 2$, leading to the release of PUFAs from the cell membrane lipid pool [160163]. The released PUFAs, especially $n-3$ PUFAs, suppress the production of IL-6, TNF- $\alpha$ and VEGF and inhibit activation of leukocytes [19-21, 98, $136,139,164]$. This suggests that one purpose of activation of PLA2 and subsequent release of PUFAs is to suppress inappropriate production of IL-6, TNF- $\alpha$, VEGF, adhesion molecules and free radicals. Thus, PUFAs and their metabolites exert negative feed-back regulation on pro-inflammatory molecules. Since DME, DR and AMD are pro-inflammatory conditions, it is suggested that PUFAs and their products have a role in DME, DR and AMD. The fact that PUFAs and their anti-inflammatory products lipoxins, resolvins, protectins and maresins suppress IL-6, TNF- $\alpha$, VEGF and ROS production lends support to this suggestion [19-21, 69-71, 98, 103-107, 136, 139]. Based on this evidence, in-depth studies are needed to delineate the role of PUFAs and their metabolites in DME, $D R$ and $A M D$ and exploit the knowledge gained to develop suitable therapeutic strategies. It is noteworthy that AA, EPA and DHA are also metabolized by cytochrome P450 enzymes to form various respective epoxyeicosatrienoic acids (EETs) that have potent anti-inflammatory actions [164, 165] (see Figure 2). The possible role of these EETs and hydroxyeicosatetraenoic acids (HETEs) in DME, DR and AMD also needs to be evaluated.

Further support for the role of PUFAs and their metabolites in DR, AMD and DME is derived from a recent study wherein it was noted that low serum adiponectin concentrations positively correlate with retinopathy of prematurity (ROP), which mimics DR in several aspects, and serum adiponectin concentrations positively correlated with serum $\omega-3$ PUFA concentrations. In addition, in mouse with oxygen-induced retinopathy, serum total adiponectin concentrations were increased by $\omega-3$ PUFA feed. Dietary $\omega-3$ PUFA suppression of neovascularization was reduced from $70 \%$ to $10 \%$ with adiponectin deficiency. APN receptors could be localized in the retina, particularly in pathologic neovessels. These findings indicate that increasing adiponectin by $\omega-3$ PUFA supplementation to preterm infants may suppress ROP [166]. These results are interesting since adiponectin receptor 1 (AdipoR1) ablation resulted in DHA reduction in retinal pigment epithelium (RPE). Adipo $R 1^{(-/)}$mice showed decreased photoreceptor-specific phosphatidylcholine containing PUFAs and severely attenuated electroretinograms. RPE-rich eyecup cultures from AdipoR $1^{(--)}$revealed impaired $\mathrm{DHA}$ uptake, while AdipoR1 overexpression in RPE cells enhanced their DHA uptake. These results suggest that AdipoR1 as a regulatory switch of DHA uptake, retention, conservation and elongation in photoreceptors and RPE, thus preserving photoreceptor cell integrity [167]. Since DHA forms a precursor to resolvins, protectins and maresins, this implies that deficiency of AdipoR1 could lead to reduced formation of these anti-inflammatory bioactive lipids. These results [167], coupled with the observation that adiponectin has a role in ROP [166], indicate that adiponectin deficiency seen in type 2 diabetes mellitus [168] may have a role in DME and DR. Furthermore, PUFAs enhance plasma levels of adiponectin [169] by a peroxisome proliferator-activated receptor- $\gamma$-dependent mechanism [170], whereas adiponectin enhances NO generation from vascular endothelial cells [171] and increases the secretion of anti-inflammatory cytokines $\mathrm{IL}-10$ and $\mathrm{IL}-1$ receptor antagonist (IL-1Ra) by human monocytes, macrophages, and dendritic cells and suppresses the production of IFN- $\gamma$ by LPS-stimulated human macrophages [172] and Toll-like receptor (TLR)-induced NF-кB activation [173], events that are of benefit in the prevention of DR, AMD and DME. It is likely that the actions of adiponectin enumerated above could be ascribed to its ability to enhance DHA and, possibly, uptake of other PUFAs and thus augment the production of lipoxins, resolvins, protectins and maresins.

The proposal that inflammatory events have a role in DME, DR and AMD is further supported by the recent observation that use of fibrates and statins may be of benefit in the prevention and management of DR [174-176]. These results are interesting since fibrates are known to have antioxidant and anti-inflammatory actions [177], while statins seem to bring about some, if not all, of their actions by modulating the metabolism of PUFAs and enhancing the formation of LXA4 [178-180]. Furthermore, both fibrates and PUFAs function as PPAR agonists [177, 181], implying that fibrates may actually mediate some of their actions by acting on the metabolism of PUFAs and, perhaps, enhance the formation of LXA4.

\section{Conclusions}

Based on the preceding discussion, it is evident that DME, DR and AMD are likely to be inflammatory conditions due to the presence of enhanced plasma (and possibly, in the vitreal fluid) concentrations of pro-inflammatory cytokines and prostaglandins, leukotrienes and VEGF and a deficiency of anti-inflammatory cytokines and lipoxins, resolvins, protectins and maresins. This implies that one can measure plasma and vitreal levels of 
various PUFAs and their products (including various prostaglandins, leukotrienes, thromboxanes and lipoxins, resolvins, protectins and maresins and, if possible, various cytokines and VEGF) and correlate their concentrations with various stages of DME, DR and AMD, response to therapy and progression of disease. The results of such studies may give clues as to when lipoxins, resolvins, protectins, maresins and epoxy products could be employed in the prevention and management of $D M E, D R$ and AMD, which may prove to be better than the current anti-VEGF therapy $[7,182,183]$.

\section{Conflict of interest}

The author declares no conflict of interest.

\section{References}

1. Tranos PG, Wickremasinghe SS, Stangos NT, Topouzis F, Tsinopoulos I, Pavesio CE. Macular edema. Surv Ophthalmol 2004; 49: 470-90.

2. Cummings M, Cunha-Vaz J. Treatment of neovascular age-related macular degeneration in patients with diabetes. Clin Ophthalmol 2008; 2: 369-75.

3. Scholl S, Augustin A, Loewenstein A, Rizzo S, Kupperman B. General pathophysiology of macular edema. Eur J Ophthalmol 2011; 21 Suppl. 6: S10-9.

4. Funatsu H, Yamashita H, Ikeda T, Nakanishi Y, Kitano S, Hori S. Angiotensin II and vascular endothelial growth factor in the vitreous fluid of patients with diabetic macular edema and other retinal disorders. Am J Ophthalmol 2002; 133: 537-43.

5. Funatsu H, Yamashita H, Ikeda T, Mimura T, Eguchi $S$, Hori S. Vitreous levels of interleukin-6 and vascular endothelial growth factor are related to diabetic macular edema. Ophthalmology 2003; 110: 1690-6.

6. Funatsu H, Yamashita H, Ikeda T, Mimura T, Shimizu E, Hori S. Relation of diabetic macular edema to cytokines and posterior vitreous detachment. Am J Ophthalmol 2003; 135: 321-7.

7. Das UN. Lipoxins, resolvins, and protectins in the prevention and treatment of diabetic macular edema and retinopathy. Nutrition 2013; 29: 1-7.

8. Bansal S, Chawla D, Siddarth M, Banerjee BD, Madhu SV, Tripathi AK. A study on serum advanced glycation end products and its association with oxidative stress and paraoxonase activity in type 2 diabetic patients with vascular complications. Clin Biochem 2013; 46: 109-14.

9. Mandal LK, Choudhuri S, Dutta D, et al. Oxidative stress-associated neuroretinal dysfunction and nitrosative stress in diabetic retinopathy. Can J Diabetes 2013; 37: 401-7.

10. Hein TW, Potts LB, Xu W, Yuen IZ, Kuo L. Temporal development of retinal arteriolar endothelial dysfunction in porcine type 1 diabetes. Invest Ophthalmol Vis Sci 2012; 53: 7943-9.

11. Othman A, Ahmad S, Megyerdi S, et al. 12/15-Lipoxygenase-derived lipid metabolites induce retinal endothelial cell barrier dysfunction: contribution of NADPH oxidase. PLoS One 2013; 8: e57254.

12. Noda K, Nakao S, Ishida S, Ishibashi T. Leukocyte adhesion molecules in diabetic retinopathy. J Ophthalmol 2012; 2012: 279037
13. Gustavsson C, Agardh CD, Zetterqvist AV, Nilsson J, Agardh E, Gomez MF. Vascular cellular adhesion molecule-1 (VCAM-1) expression in mice retinal vessels is affected by both hyperglycemia and hyperlipidemia. PLoS One 2010; 5: e12699.

14. Stem MS, Gardner TW. Neurodegeneration in the pathogenesis of diabetic retinopathy: molecular mechanisms and therapeutic implications. Curr Med Chem 2013; 20: 3241-50.

15. Roy MS, Janal MN, Crosby J, Donnelly R. Inflammatory biomarkers and progression of diabetic retinopathy in African Americans with type 1 diabetes. Invest Ophthalmol Vis Sci 2013; 54: 5471-80.

16. Haas P, Kubista KE, Krugluger W, Huber J, Binder S. Impact of visceral fat and pro-inflammatory factors on the pathogenesis of age-related macular degeneration. Acta Ophthalmol 2015; 93: 533-8.

17. Levy O, Calippe B, Lavalette S, et al. Apolipoprotein E promotes subretinal mononuclear phagocyte survival and chronic inflammation in age-related macular degeneration. EMBO Mol Med 2015; 7: 211-26.

18. Agawa T, Usui Y, Wakabayashi Y, et al. Profile of intraocular immune mediators in patients with age-related macular degeneration and the effect of intravitreal bevacizumab injection. Retina 2014; 34: 1811-8.

19. Das UN. Lipoxins, resolvins, protectins, maresins and nitrolipids and their clinical implications with specific reference to cancer: part I. Clin Lipidol 2013; 8: 437-63.

20. Das UN. Lipoxins, resolvins, protectins, maresins and nitrolipids and their clinical implications with specific reference to diabetes mellitus and other diseases: Part II. Clin Lipidol 2013; 8: 465-80.

21. Das UN. Essential fatty acids and their metabolites could function as endogenous HMG-CoA reductase and ACE enzyme inhibitors, anti-arrhythmic, anti-hypertensive, anti-atherosclerotic, anti-inflammatory, cytoprotective, and cardioprotective molecules. Lipids Health Dis 2008; 7: 37.

22. Adamis AP. Is diabetic retinopathy an inflammatory disease? Br J Ophthalmol 2002; 86: 363-5.

23. Rangasamy S, McGuire PG, Das A. Diabetic retinopathy and inflammation: novel therapeutic targets. Middle East Afr J Ophthalmol 2012; 19: 52-9.

24. Klaassen I, Van Noorden CJ, Schlingemann RO. Molecular basis of the inner blood-retinal barrier and its breakdown in diabetic macular edema and other pathological conditions. Prog Retin Eye Res 2013; 34: 19-48.

25. Lutty GA, Cao J, McLeod DS. Relationship of polymorphonuclear leukocytes to capillary dropout in the human diabetic choroid. Am J Pathol 1997; 151: 707-14.

26. Joussen AM, Murata T, Tsujikawa A, Kirchhof B, Bursell SE, Adamis AP. Leukocyte-mediated endothelial cell injury and death in the diabetic retina. Am J Pathol 2001; 158: 147-52.

27. Liu RT, Gao J, Cao S, et al. Inflammatory mediators induced by amyloid-beta in the retina and RPE in vivo: implications for inflammasome activation in age-related macular degeneration. Invest Ophthalmol Vis Sci 2013; 54: 2225-37.

28. Lin T, Walker GB, Kurji K, et al. Parainflammation associated with advanced glycation end product stimulation of RPE in vitro: implications for age-related degenerative diseases of the eye. Cytokine 2013; 62: 369-81.

29. Whitcup SM, Sodhi A, Atkinson JP, et al. The role of the immune response in age-related macular degeneration. Int J Inflam 2013; 2013: 348092. 
30. Cruz-Guilloty F, Saeed AM, Duffort S, et al. T cells and macrophages responding to oxidative damage cooperate in pathogenesis of a mouse model of age-related macular degeneration. PLoS One 2014; 9: e88201.

31. Canas-Barouch F, Miyamoto K, Allport JR, et al. Integrin-mediated neutrophil adhesion and retinal leukostasis in diabetes. Invest Ophthalmol Vis Sci 2000; 41: 1153-8.

32. Schoenberger SD, Kim SJ, Sheng J, Rezaei KA, Lalezary M, Cherney E. Increased prostaglandin E2 (PGE2) levels in proliferative diabetic retinopathy, and correlation with VEGF and inflammatory cytokines. Invest Ophthalmol Vis Sci 2012; 53: 5906-11.

33. Klein R, Myers CE, Cruickshanks KJ, et al. Markers of inflammation, oxidative stress, and endothelial dysfunction and the 20-year cumulative incidence of early age-related macular degeneration: the Beaver Dam Eye Study. JAMA Ophthalmol 2014; 132: 446-55.

34. Jung SH, Kim KA, Sohn SW, Yang SJ. Association of aqueous humor cytokines with the development of retinal ischemia and recurrent macular edema in retinal vein occlusion. Invest Ophthalmol Vis Sci 2014; 55 : 2290-6.

35. Liu RT, Gao J, Cao S, et al. Inflammatory mediators induced by amyloid-beta in the retina and RPE in vivo: implications for inflammasome activation in age-related macular degeneration. Invest Ophthalmol Vis Sci 2013; 54: 2225-37.

36. Kauppinen A, Niskanen $H$, Suuronen T, Kinnunen K, Salminen A, Kaarniranta K. Oxidative stress activates NLRP3 inflammasomes in ARPE-19 cells: implications for age-related macular degeneration (AMD). Immunol Lett 2012; 147: 29-33.

37. Seddon JM, George S, Rosner B, Rifai N. Progression of age-related macular degeneration: prospective assessment of C-reactive protein, interleukin 6, and other cardiovascular biomarkers. Arch Ophthalmol 2005; 123: 774-82.

38. Miyamoto K, Hiroshiba N, Tsujikawa A, Ogura Y. In vivo demonstration of increased leukocyte entrapment in retinal microcirculation of diabetic rats. Invest Ophthalmol Vis Sci 1998; 39: 2190-4.

39. Penfold PL, Provis JM, Billson FA. Age-related macular degeneration: ultrastructural studies of the relationship of leucocytes to angiogenesis. Graefes Arch Clin Exp Ophthalmol 1987; 225: 70-6.

40. Juel HB, Faber C, Udsen MS, Folkersen L, Nissen MH. Chemokine expression in retinal pigment epithelial ARPE-19 cells in response to coculture with activated T cells. Invest Ophthalmol Vis Sci 2012; 53: 8472-80.

41. Vidinova CN, Vidinov KN. Macrophages in the ultrastructure of PDR membranes and subretinal AMD membranes: a possible role in neoangiogenesis. Klin Monbl Augenheilkd 2012; 229: 1204-8.

42. Yang D, Elner SG, Chen X, Field MG, Petty HR, Elner VM. MCP-1-activated monocytes induce apoptosis in human retinal pigment epithelium. Invest Ophthalmol Vis Sci 2011; 52: 6026-34.

43. Joussen AM, Murata T, Tsujikawa A, Kirchhof B, Bursell SE, Adamis AP. Leukocyte-mediated endothelial cell injury and death in the diabetic retina. Am J Pathol 2001; 158: 147-52.

44. Joussen AM, Poulaki V, Le ML, et al. A central role for inflammation in the pathogenesis of diabetic retinopathy. FASEB J 2004; 18: 1450-2.

45. Powell EDU, Field RA. Diabetic retinopathy in rheumatoid arthritis. Lancet 1964; 2: 17-8.
46. Kern TS, Engerman RL. Pharmacological inhibition of diabetic retinopathy: aminoguanidine and aspirin. Diabetes 2001; 50: 1636-42.

47. Saishin Y, Saishin Y, Takahashi K, Melia M, Vinores SA, Campochiaro PA. Inhibition of protein kinase $C$ decreases prostaglandin-induced breakdown of the blood-retinal barrier. J Cell Physiol 2003; 195: 210-9.

48. Collier A, Tymkewycz P, Armstrong R, Young RJ, Jones RL, Clarke BF. Increased platelet thromboxane receptor sensitivity in diabetic patients with proliferative retinopathy. Diabetologia 1986; 29: 471-4.

49. Schoenberger SD, Kim SJ, Sheng J, Rezaei KA, Lalezary M, Cherney E. Increased prostaglandin E2 (PGE2) levels in proliferative diabetic retinopathy, and correlation with VEGF and inflammatory cytokines. Invest Ophthalmol Vis Sci 2012; 53: 5906-11.

50. Barajas-Espinosa A, Ni NC, Yan D, Zarini S, Murphy RC, Funk CD. The cysteinyl leukotriene 2 receptor mediates retinal edema and pathological neovascularization in a murine model of oxygen-induced retinopathy. FASEB J 2012; 26: 1100-9.

51. Augustin AJ, Diehm C, Grieger F, Bentz J. Alprostadil infusion in patients with dry age related macular degeneration: a randomized controlled clinical trial. Expert Opin Investig Drugs 2013; 22: 803-12.

52. Komori T, Fujii S, Nogi O, Ohashi M, Sasakawa O, Yamamoto K. Prostacyclin production reduced in diabetics with vascular complications. Jpn J Med 1985; 24: 231-5.

53. Naveh N, Belkin M, Ben-Chaim O, Weissman C, Treister $\mathrm{G}$. Prostanoids in the vitreous of diabetic and nondiabetic human eyes with retinal detachment. Ophthalmic Res 1990; 22: 3-11.

54. Franco VW. PGI2 may aid prevention of diabetic retinopathy. Diabetes Care 1986; 9: 104.

55. Douros S, Phillips BA, Nadel A, Obstbaum SA. Human vitreal prostaglandin levels and proliferative diabetic retinopathy. Doc Ophthalmol 2001; 103: 27-34.

56. Hardy P, Beauchamp M, Sennlaub F, et al. New insights into the retinal circulation: inflammatory lipid mediators in ischemic retinopathy. Prostaglandins Leukot Essent Fatty Acids 2005; 72: 301-25.

57. Hetzel S, DeMets D, Schneider R, et al. Aspirin increases nitric oxide formation in chronic stable coronary disease. J Cardiovasc Pharmacol Ther 2013; 18: 217-21.

58. Hennekens $\mathrm{CH}$, Schneider WR, Pokov A, et al. A randomized trial of aspirin at clinically relevant doses and nitric oxide formation in humans. J Cardiovasc Pharmacol Ther 2010; 15: 344-8.

59. O'Kane P, Xie L, Liu Z, et al. Aspirin acetylates nitric oxide synthase type 3 in platelets thereby increasing its activity. Cardiovasc Res 2009; 83: 123-30.

60. Vainio M, Riutta A, Koivisto AM, Mäenpää J. Prostacyclin, thromboxane A and the effect of low-dose ASA in pregnancies at high risk for hypertensive disorders. Acta Obstet Gynecol Scand 2004; 83: 1119-23.

61. De La Cruz JP, González-Correa JA, Guerrero A, Márquez E, Martos F, Sánchez De La Cuesta F. Differences in the effects of extended-release aspirin and plain-formulated aspirin on prostanoids and nitric oxide in healthy volunteers. Fundam Clin Pharmacol 2003; 17: 363-72.

62. Fiorucci S, Distrutti E, Mencarelli A, et al. Evidence that 5-lipoxygenase and acetylated cyclooxygenase 2-derived eicosanoids regulate leukocyte-endothelial adherence in response to aspirin. $\mathrm{Br} J$ Pharmacol 2003; 139: 1351-9. 
63. Gilroy DW. New insights into the anti-inflammatory actions of aspirin-induction of nitric oxide through the generation of epi-lipoxins. Mem Inst Oswaldo Cruz 2005; 100 Suppl. 1: 49-54.

64. Prescott D, McKay DM. Aspirin-triggered lipoxin enhances macrophage phagocytosis of bacteria while inhibiting inflammatory cytokine production. Am J Physiol Gastrointest Liver Physiol 2011; 301: G487-97.

65. Du Y, Sarthy VP, Kern TS. Interaction between NO and COX pathways in retinal cells exposed to elevated glucose and retina of diabetic rats. Am J Physiol Regul Integr Comp Physiol 2004; 287: R735-41.

66. Paul-Clark MJ, Van Cao T, Moradi-Bidhendi N, Cooper D, Gilroy DW. 15-epi-lipoxin A4-mediated induction of nitric oxide explains how aspirin inhibits acute inflammation. J Exp Med 2004; 200: 69-78.

67. Bratt J, Gyllenhammar H. The role of nitric oxide in lipoxin A4-induced polymorphonuclear neutrophil-dependent cytotoxicity to human vascular endothelium in vitro. Arthritis Rheum 1995; 38: 768-76.

68. Tamaoki J, Tagaya E, Yamawaki I, Konno K. Lipoxin A4 inhibits cholinergic neurotransmission through nitric oxide generation in the rabbit trachea. Eur J Pharmacol 1995; 287: 233-8.

69. Wu Y, Zhai H, Wang Y, et al. Aspirin-triggered lipoxin $\mathrm{A}_{4}$ attenuates lipopolysaccharide-induced intracellular ROS in BV2 microglia cells by inhibiting the function of NADPH oxidase. Neurochem Res 2012; 37: 1690-6.

70. Börgeson E, Lönn J, Bergström I, et al. Lipoxin $A_{4}$ inhibits porphyromonas gingivalis-induced aggregation and reactive oxygen species production by modulating neutrophil-platelet interaction and CD11b expression. Infect Immun 2011; 79: 1489-97.

71. Nascimento-Silva V, Arruda MA, Barja-Fidalgo C, Fierro IM. Aspirin-triggered lipoxin A4 blocks reactive oxygen species generation in endothelial cells: a novel antioxi dative mechanism. Thromb Haemost 2007; 97: 88-98.

72. Lee TS, Chau LY. Heme oxygenase-1 mediates the antiinflammatory effect of interleukin-10 in mice. Nat Med 2002; 8: 240-6.

73. Ricchetti GA, Williams LM, Foxwell BM. Heme oxygenase 1 expression induced by IL-10 requires STAT-3 and phosphoinositol-3 kinase and is inhibited by lipopolysaccharide. J Leukoc Biol 2004; 76: 719-26.

74. Nascimento-Silva V, Arruda MA, Barja-Fidalgo C, Villela CG, Fierro IM. Novel lipid mediator aspirin-triggered lipoxin A4 induces heme oxygenase- 1 in endothelial cells. Am J Physiol Cell Physiol 2005; 289: C557-63.

75. Jin SW, Zhang L, Lian QQ, et al. Posttreatment with aspirin-triggered lipoxin A4 analog attenuates lipopolysaccharide-induced acute lung injury in mice: the role of heme oxygenase-1. Anesth Analg 2007; 104: 369-77.

76. Chen XQ, Wu SH, Zhou Y, Tang YR. Lipoxin A4-induced heme oxygenase- 1 protects cardiomyocytes against hypoxia/reoxygenation injury via p38 MAPK activation and Nrf2/ARE complex. PLoS One 2013; 8: e67120.

77. Biteman B, Hassan IR, Walker E, et al. Interdependence of lipoxin A4 and heme-oxygenase in counter-regulating inflammation during corneal wound healing. FASEB J 2007; 21: 2257-66

78. Katoh T, Lakkis FG, Makita N, Badr KF. Co-regulated expression of glomerular 12/15-lipoxygenase and interleukin-4 mRNAs in rat nephrotoxic nephritis. Kidney Int 1994; 46: 341-9.

79. Das UN. Lipoxins as biomarkers of lupus and other inflammatory conditions. Lipid Health Dis 2011; 10: 76.
80. Das UN. Radiation resistance, invasiveness and metastasis are inflammatory events that could be suppressed by lipoxin A4. Prostaglandins Leukot Essen Fatty Acids 2012; 86: 3-11.

81. Serhan CN, Chiang N, Van Dyke TE. Resolving inflammation: dual antiinflammatory and pro-resolution lipid mediators. Nat Rev Immunol 2008; 8: 349-61.

82. Rhodes LE, Gledhill K, Masoodi M, et al. The sunburn response in human skin is characterized by sequential eicosanoid profiles that may mediate its early and late phases. FASEB J 2009; 23: 3947-56.

83. Harizi H, Norbert G. Inhibition of IL-6, TNF-alpha, and cyclooxygenase-2 protein expression by prostaglandin E2-induced IL-10 in bone marrow-derived dendritic cells. Cell Immunol 2004; 228: 99-109.

84. Harizi H, Juzan M, Pitard V, Moreau JF, Gualde N. Cyclooxygenase-2-issued prostaglandin e(2) enhances the production of endogenous IL-10, which down-regulates dendritic cell functions. J Immunol 2002; 168: 2255-63.

85. Harizi H, Juzan M, Moreau JF, Gualde N. Prostaglandins inhibit 5-lipoxygenase-activating protein expression and leukotriene B4 production from dendritic cells via an IL-10-dependent mechanism. J Immunol 2003; 170: 139-46.

86. Vinores SA, Youssri Al, Luna JD, et al. Upregulation of vascular endothelial growth factor in ischemic and non-ischemic human and experimental retinal disease. Histol Histopathol 1997; 12: 99-109.

87. Funatsu $\mathrm{H}$, Yamashita H, Noma H, Mimura T, Yamashita T, Hori S. Increased levels of vascular endothelial growth factor and interleukin-6 in the aqueous humor of diabetics with macular edema. Am J Ophthalmol 2002; 133: 70-7.

88. Koczy-Baron E, Kasperska-Zając A. The role of vascular endothelial growth factor in inflammatory processes. Postepy Hig Med Dosw 2014; 68: 57-65.

89. Lee CG, Link $H$, Baluk $P$, et al. Vascular endothelial growth factor (VEGF) induces remodeling and enhances Th2-mediated sensitization and inflammation in the lung. Nat Med 2004; 10: 1095-103.

90. Bai Y, Ma JX, Guo J, et al. Müller cell-derived VEGF is a significant contributor to retinal neovascularization. J Pathol 2009; 219: 446-54.

91. Selim KM, Sahan D, Muhittin T, Osman C, Mustafa O. Increased levels of vascular endothelial growth factor in the aqueous humor of patients with diabetic retinopathy. Indian J Ophthalmol 2010; 58: 375-9.

92. Tsai $\mathrm{CH}$, Chiang YC, Chen HT, Huang PH, Hsu HC, Tang $\mathrm{CH}$. High glucose induces vascular endothelial growth factor production in human synovial fibroblasts through reactive oxygen species generation. Biochim Biophys Acta 2013; 1830: 2649-58.

93. Akirav EM, Baquero MT, Opare-Addo LW, et al. Glucose and inflammation control islet vascular density and beta-cell function in NOD mice: control of islet vasculature and vascular endothelial growth factor by glucose. Diabetes 2011; 60: 876-83.

94. Gupta K, Kshirsagar S, Li W, et al. VEGF prevents apoptosis of human microvascular endothelial cells via opposing effects on MAPK/ERK and SAPK/JNK signaling. Exp Cell Res 1999; 247: 495-504.

95. Alon T, Hemo I, Itin A, Pe'er J, Stone J, Keshet E. Vascular endothelial growth factor acts as a survival factor for newly formed retinal vessels and has implications for retinopathy of prematurity. Nat Med 1995; 1: 1024-8.

96. Waisbourd M, Goldstein M, Loewenstein A. Treatment of diabetic retinopathy with anti-VEGF drugs. Acta Ophthalmol 2011; 89: 203-7. 
97. Schlingemann RO, Witmer AN. Treatment of retinal diseases with VEGF antagonists. Prog Brain Res 2009; 175: 253-67.

98. Kumar GS, Das UN, Kumar KV, et al. Effect of n-6 and n-3 fatty acids on the proliferation and secretion of TNF and IL-2 by human lymphocytes in vitro. Nutr Res 1992; 12: 815-23.

99. Cicero AFG, Tartagni E. Diet, dietary supplements and age-related macular degeneration (AMD). Nutrients 2014; 13: 5-11.

100. Zhao Q, Shao L, Hu X, et al. Lipoxin a4 preconditioning and postconditioning protect myocardial ischemia/ reperfusion injury in rats. Mediators Inflamm 2013; 2013: 231351.

101. Chen Z, Wu Z, Huang C, et al. Effect of lipoxin A4 on myocardial ischemia reperfusion injury following cardiac arrest in a rabbit model. Inflammation 2013; 36: 468-75.

102. Das UN. Arachidonic acid and lipoxin A4 as possible endogenous anti-diabetic molecules. Prostaglandins Leukot Essent Fatty Acids 2013; 88: 201-10.

103. Bento AF, Claudino RF, Dutra RC, Marcon R, Calixto JB. Omega-3 fatty acid-derived mediators 17(R)-hydroxy docosahexaenoic acid, aspirin-triggered resolvin D1 and resolvin D2 prevent experimental colitis in mice. J Immunol 2011; 187: 1957-69.

104. Wang B, Gong X, Wan JY, et al. Resolvin D1 protects mice from LPS-induced acute lung injury. Pulm Pharmacol Ther 2011; 24: 434-41.

105. Wu SH, Lu C, Dong L, Zhou GP, He ZG, Chen ZQ. Lipoxin A4 inhibits TNF-alpha-induced production of interleukins and proliferation of rat mesangial cells. Kidney Int 2005; 68: 35-46.

106. Zhuang W, Wang G, Li L, Lin G, Deng Z. Omega-3 polyunsaturated fatty acids reduce vascular endothelial growth factor production and suppress endothelial wound repair. J Cardiovasc Transl Res 2013; 6: 287-93.

107. Calviello G, Di Nicuolo F, Gragnoli S, et al. n-3 PUFAs reduce VEGF expression in human colon cancer cells modulating the COX-2/PGE2 induced ERK-1 and -2 and HIF-1alpha induction pathway. Carcinogenesis 2004; 25: 2303-10.

108. Harada S, Nagy JA, Sullivan KA, et al. Induction of vascular endothelial growth factor expression by prostaglandin E2 and E1 in osteoblasts. J Clin Invest 1994; 93: 2490-6.

109. Tsuzuki T, Shibata A, Kawakami Y, Nakagawa K, Miyazawa T. Conjugated eicosapentaenoic acid inhibits vascular endothelial growth factor-induced angiogenesis by suppressing the migration of human umbilical vein endothelial cells. J Nutr 2007; 137: 641-6.

110. Chen Y, Hao H, He S, et al. Lipoxin A4 and its analogue suppress the tumor growth of transplanted $\mathrm{H} 22$ in mice: the role of antiangiogenesis. Mol Cancer Ther 2010; 9: 2164-74.

111. Sapieha P, Stahl A, Chen J, et al. 5-Lipoxygenase metabolite 4-HDHA is a mediator of the antiangiogenic effect of omega-3 polyunsaturated fatty acids. Sci Transl Med 2011; 3: 69ra12.

112. Connor KM, SanGiovanni JP, Lofqvist C, et al. Increased dietary intake of omega-3-polyunsaturated fatty acids reduces pathological retinal angiogenesis. Nat Med 2007; 13: 868-73.

113. Zhuang W, Wang G, Li L, Lin G, Deng Z. Omega-3 polyunsaturated fatty acids reduce vascular endothelial growth factor production and suppress endothelial wound repair. J Cardiovasc Transl Res 2013; 6: 287-93.
114. Zhang G, Panigrahy D, Mahakian LM, et al. Epoxy metabolites of docosahexaenoic acid (DHA) inhibit angiogenesis, tumor growth, and metastasis. Proc Natl Acad Sci U S A 2013; 110: 6530-5.

115. Tikhonenko M, Lydic TA, Opreanu M, et al. N-3 polyunsaturated fatty acids prevent diabetic retinopathy by inhibition of retinal vascular damage and enhanced endothelial progenitor cell reparative function. PLoS One 2013; 8: e55177.

116. Connor KM, SanGiovanni JP, Lofqvist C, et al. Increased dietary intake of omega-3 polyunsaturated fatty acids reduces pathological retinal angiogenesis. Nat Med 2007; 7: 868-73.

117. Ma Q, Shen JH, Shen SR, Das UN. Bioactive lipids in pathological retinopathy. Crit Rev Food Sci Nutr 2014; 54: 1-16.

118. Shen J, Bi YL, Das UN. Potential role of polyunsaturated fatty acids in diabetic retinopathy. Arch Med Sci 2014; 10: 1167-74.

119. Shen J, Shen S, Das UN. Effect of essential fatty acids on glucose-induced cytotoxicity to retinal vascular endothelial cells. Lipid Health Dis 2012; 11: 90.

120. Shen J, Ma Q, Shen S, Xu GT, Das UN. Effect of alpha-linolenic acid on streptozotocin-induced diabetic retinopathy indices in vivo. Arch Med Sci 2013; 44: 514-20.

121. Liu XH, Kirschenbaum A, Yao S, Lee R, Holland JF, Levine AC. Inhibition of cyclooxygenase-2 suppresses angiogenesis and the growth of prostate cancer in vivo. J Urol 2000; 164: 820-5.

122. Liu XH, Kirschenbaum A, Yao S, et al. Upregulation of vascular endothelial growth factor by cobalt chloride-simulated hypoxia is mediated by persistent induction of cyclooxygenase- 2 in a metastatic human prostate cancer cell line. Clin Exp Metastasis 1999; 17: 687-94.

123. Tang Y, Wang MT, Chen Y, et al. Downregulation of vascular endothelial growth factor and induction of tumor dormancy by 15-lipoxygenase-2 in prostate cancer. Int J Cancer 2009; 124: 1545-51.

124. Thomas MA, O'Grady GE, Swartz SL. Prostaglandin levels in human vitreous. Br J Ophthalmol 1985; 69: 275-9.

125. Divangahi M, Behar SM, Remold H. Dying to live: how the death modality of the infected macrophage affects immunity to tuberculosis. Adv Exp Med Biol 2013; 783: 103-20.

126. Wang B, Gong X, Wan JY, et al. Resolvin D1 protects mice from LPS-induced acute lung injury. Pulm Pharmacol Ther 2011; 24: 434-41.

127. Menezes-de-Lima O Jr, Kassuya CA, Nascimento AF, Henriques MD, Calixto JB. Lipoxin A4 inhibits acute edema in mice: implications for the anti-edematogenic mechanism induced by aspirin. Prostaglandins Other Lipid Mediat 2006; 80: 123-35.

128. Wu A, Ying Z, Gomez-Pinilla F. Dietary omega-3 fatty acids normalize BDNF levels, reduce oxidative damage, and counteract learning disability after traumatic brain injury in rats. J Neurotrauma 2004; 21: 1457-67.

129. Das UN. Autism as a disorder of deficiency of brain-derived neurotrophic factor and altered metabolism of polyunsaturated fatty acids. Nutrition 2013; 29: $1175-85$.

130. Vetrivel U, Ravichandran SB, Kuppan K, Mohanlal J, Das UN, Narayanasamy A. Agonistic effect of polyunsaturated fatty acids (PUFAs) and its metabolites on brain-derived neurotrophic factor (BDNF) through molecular docking simulation. Lipids Health Dis 2012; 11: 109. 
131. Das UN. Is obesity an inflammatory condition? Nutrition 2001; 17: 953-66.

132. Ramos EJB, Xu Y, Romanova I, et al. Is obesity an inflammatory disease? Surgery 2003; 134: 329-35.

133. Das UN. Renal sympathetic denervation for resistant hypertension - an alternate view. Med Hypotheses 2013; 81: 1135-6.

134. Vijay Kumar K, Das UN. Are free radicals involved in the pathobiology of human essential hypertension? Free Rad Res Commun 1993; 19: 59-66.

135. Das UN. Hypertension as a low-grade systemic inflammatory condition that has its origins in the perinatal period. J Assoc Physicians India 2006; 54: 133-42.

136. Das UN. Metabolic syndrome pathophysiology: the role of essential fatty acids and their metabolites. Wiley-Blackwell Publishers, Ames, IA, USA, 2010.

137. Stępień M, Stępień A, Wlazeł RN, Paradowski M, Banach $M$, Rysz J. Obesity indices and inflammatory markers in obese non-diabetic normo- and hypertensive patients: a comparative pilot study. Lipids Health Dis 2014; 13: 29.

138. Rysz J, Banach M, Stolarek RA, et al. Serum matrix metalloproteinases MMP-2 and MMP-9 and metalloproteinase tissue inhibitors TIMP-1 and TIMP-2 in diabetic nephropathy. J Nephrol 2007; 20: 444-52.

139. Das UN. Molecular Basis of Health and Disease. Springer, New York 2011.

140. Waszczykowska A, Goś R, Waszczykowska E, Dziankowska-Bartkowiak B, Jurowski P. Prevalence of ocular manifestations in systemic sclerosis patients. Arch Med Sci 2013; 9: 1107-13.

141. Suryaprabha P, Das UN, Ramesh G, Kumar KV, Kumar KS. Reactive oxygen species, lipid peroxides and essential fatty acids in patients with rheumatoid arthritis and systemic lupus erythematosus. Prostaglandins Leukot Essent Fatty Acids 1991; 43: 251-5.

142. Das UN. Beneficial effect of eicosapentaenoic acid and docosahexaenoic acid in the management of systemic lupus erythematosus and its relationship to the cytokine network. Prostaglandins Leukot Essent Fatty Acids 1994; 51: 207-13.

143. Das UN. Beneficial action(s) of eicosapentaenoic acid/ docosahexaenoic acid and nitric oxide in systemic lupus erythematosus. Med Sci Res 1995; 23: 723-6.

144. Krishna Mohan I, Das UN. Oxidant stress, anti-oxidants and essential fatty acids in systemic lupus erythematosus. Prostaglandins Leukot Essent Fatty Acids 1997; 56: $193-8$.

145. Das UN. Oxidants, anti-oxidants, essential fatty acids, eicosanoids, cytokines, gene/oncogene expression and apoptosis in systemic lupus erythematosus. J Assoc Physicians India 1998; 46: 630-4.

146. Das UN. Current and emerging strategies for the treatment and management of systemic lupus erythematosus based on molecular signatures of acute and chronic inflammation. J Inflammation Res 2010; 3: 143-70.

147. Simó R, Hernández C. Prevention and treatment of diabetic retinopathy: evidence from large, randomized trials. The emerging role of fenofibrate. Rev Recent Clin Trials 2012; 7: 71-80.

148. Moshfeghi AA, Rosenfeld PJ, Puliafito CA, et al. Systemic bevacizumab (Avastin) therapy for neovascular age-related macular degeneration: twenty-four-week results of an uncontrolled open-label clinical study. Ophthalmology 2006; 113: 2002.e1-12.

149. Chakravarthy U, Harding SP, Rogers CA, et al; IVAN study investigators. Alternative treatments to inhibit VEGF in age-related choroidal neovascularisation: 2-year findings of the IVAN randomised controlled trial. Lancet 2013; 382: 1258-67.

150. Kernt M, Cserhati S, Seidensticker F, et al. Improvement of diabetic retinopathy with intravitreal ranibizumab. Diabetes Res Clin Pract 2013; 100: e11-3.

151. Das UN. Essential fatty acid metabolism in patients with essential hypertension, diabetes mellitus and coronary heart disease. Prostaglandins Leukot Essent Fatty Acids 1995; 52: 387-91.

152. Huang T, Asimi S, Lou D, Li D. Plasma phospholipid polyunsaturated fatty acids and homocysteine in Chinese type 2 diabetes patients. Asia Pac J Clin Nutr 2012; 21 : 394-9.

153. Nishida S, Segawa T, Murai I, Nakagawa S. Long-term melatonin administration reduces hyperinsulinemia and improves the altered fatty-acid compositions in type 2 diabetic rats via the restoration of delta- 5 desaturase activity. J Pineal Res 2002; 32: 26-33.

154. Krishna Mohan I, Das UN. Prevention of chemically-induced diabetes mellitus in experimental animals by polyunsaturated fatty acids. Nutrition 2001; 17: 126-51.

155. Suresh Y, Das UN. Protective action of arachidonic acid against alloxan-induced cytotoxicity and diabetes mellitus. Prostaglandins Leukot Essent Fatty Acids 2001; 64: 37-52.

156. Suresh Y, Das UN. Long-chain polyunsaturated fatty acids and chemically-induced diabetes mellitus: effect of omega-6 fatty acids. Nutrition 2003; 19: 93-114.

157. Suresh Y, Das UN. Long-chain polyunsaturated fatty acids and chemically-induced diabetes mellitus: effect of omega-3 fatty acids. Nutrition 2003; 19: 213-28.

158. Liu HQ, Qiu Y, Mu Y, et al. A high ratio of dietary n-3/n-6 polyunsaturated fatty acids improves obesity-linked inflammation and insulin resistance through suppressing activation of TLR4 in SD rats. Nutr Res 2013; 33: 849-58.

159. Sailaja MMS, Das UN. Effect of prostaglandins against alloxan-induced diabetes mellitus. Prostaglandins Leukot Essent Fatty Acids 2006; 74: 39-60.

160. Boccellino M, Giovane A, Servillo L, Balestrieri C, Quagliuolo L. Fatty acid mobilized by the vascular endothelial growth factor in human endothelial cells. Lipids 2002; 37: 1047-52.

161. Chepenik KP, Diaz A, Jimenez SA. Epidermal growth factor coordinately regulates the expression of prostaglandin G/H synthase and cytosolic phospholipase A2 genes in embryonic mouse cells. J Biol Chem 1994; 269: 21786-92.

162. Adamson GM, Carlson TJ, Billings RE. Phospholipase A2 activation in cultured mouse hepatocytes exposed to tumor necrosis factor-alpha. J Biochem Toxicol 1994; 9: 181-90.

163. Liu SJ, McHowat J. Stimulation of different phospholipase A2 isoforms by TNF-alpha and IL-1beta in adult rat ventricular myocytes. Am J Physiol 1998; 275: H1462-72.

164. Ulu A, Harris TR, Morisseau C, et al. Anti-inflammatory effects of $n-3$ polyunsaturated fatty acids and soluble epoxide hydrolase inhibitors in angiotensin-II-dependent hypertension. J Cardiovasc Pharmacol 2013; 62: 285-97.

165. Zeldin DC. Epoxygenase pathways of arachidonic acid metabolism. J Biol Chem 2001; 276: 36059-62.

166. Fu Z, Lofqvist CA, Shao Z, et al. Dietary omega-3 polyunsaturated fatty acids decrease retinal neovascularization by adipose-endoplasmic reticulum stress re- 
duction to increase adiponectin. Am J Clin Nutr 2015; 101: 879-88.

167. Rice DS, Calandria JM, Gordon WC, et al. Adiponectin receptor 1 conserves docosahexaenoic acid and promotes photoreceptor cell survival. Nat Commun 2015; 6: 6228.

168. Hotta K, Funahashi T, Arita Y, et al. Plasma concentrations of a novel, adipose-specific protein, adiponectin, in type 2 diabetic patients. Arterioscler Thromb Vasc Biol 2000; 20: 1595-9.

169. Müllner E, Plasser E, Brath $\mathrm{H}$, et al. Impact of polyunsaturated vegetable oils on adiponectin levels, glycaemia and blood lipids in individuals with type 2 diabetes: a randomised, double-blind intervention study. J Hum Nutr Diet 2013; 27: 468-78.

170. Neschen S, Morino K, Rossbacher JC, et al. Fish oil regulates adiponectin secretion by a peroxisome proliferator-activated receptor-gamma-dependent mechanism in mice. Diabetes 2006; 55: 924-8.

171. Chen H, Montagnani M, Funahashi T, Shimomura I, Quon MJ. Adiponectin stimulates production of nitric oxide in vascular endothelial cells. J Biol Chem 2003; 278: 45021-6.

172. Wolf AM, Wolf D, Rumpold H, Enrich B, Tilg H. Adiponectin induces the anti-inflammatory cytokines IL-10 and IL-1RA in human leukocytes. Biochem Biophys Res Commun 2004; 323: 630-5.

173. Yamaguchi N, Argueta JG, Masuhiro Y, et al. Adiponectin inhibits Toll-like receptor family-induced signaling. FEBS Lett 2005; 579: 6821-6.

174. Wong TY, Simó R, Mitchell P. Fenofibrate - a potential systemic treatment for diabetic retinopathy? Am J Ophthalmol 2012; 154: 6-12.

175. Ansquer JC, Crimet D, Foucher C. Fibrates and statins in the treatment of diabetic retinopathy. Curr Pharm Biotechnol 2011; 12: 396-405.

176. Tuuminen R, Sahanne S, Loukovaara S. Low intravitreal angiopoietin-2 and VEGF levels in vitrectomized diabetic patients with simvastatin treatment. Acta Ophthalmol 2014; 92: 675-81.

177. Chen XR, Besson VC, Palmier B, Garcia Y, Plotkine M, Marchand-Leroux C. Neurological recovery-promoting, anti-inflammatory, and anti-oxidative effects afforded by fenofibrate, a PPAR alpha agonist, in traumatic brain injury. J Neurotrauma 2007; 24: 1119-31.

178. Das UN. Essential fatty acids as possible mediators of the actions of statins. Prostaglandins Leukot Essent Fatty Acids 2001; 65: 37-40.

179. Birnbaum Y, Ye Y, Lin Y, et al. Augmentation of myocardial production of 15 -epi-lipoxin-a4 by pioglitazone and atorvastatin in the rat. Circulation 2006; 114: 929-35.

180. Planagumà A, Pfeffer MA, Rubin G, et al. Lovastatin decreases acute mucosal inflammation via 15-epi-lipoxin A4. Mucosal Immunol 2010; 3: 270-9.

181. Gani OA. Are fish oil omega-3 long-chain fatty acids and their derivatives peroxisome proliferator-activated receptor agonists? Cardiovasc Diabetol 2008; 7: 6

182. Das UN. Is lipoxins A4 a better alternative to antiTNF-alpha antibody to prevent and treat diabetic mac ular edema and retinopathy? Med Sci Monit 2010; 16: LE13-4.

183. Das UN. Is lipoxins A4 a better alternative to anti-VEGF and anti-TNF-alpha antibody to prevent and treat age-related macular degeneration, diabetic macular edema and retinopathy? Med Sci Monit 2011; 18: LE1-2. 